\title{
Farmers' Investment on Sustainable Agricultural Practices: Evidence from Amhara Region, Ethiopia
}

\author{
Haimanot B. Atinkut ${ }^{1, ~ *, ~ A b d u l h a m i d ~ K . ~ B e d r i ², ~ A s s e f a ~ K . ~ S e n t a y e h u ~}{ }^{4}$, Dick Warren ${ }^{3}$ \\ ${ }^{1}$ Department of Rural Development and Agricultural Extension, College of Agriculture and Rural Transformation, University of Gondar, \\ Gondar, Ethiopia \\ ${ }^{2}$ Department of Environment and Development, College of Development Studies, Addis Ababa University, Addis Ababa, Ethiopia \\ ${ }^{3}$ Department of Soil Chemistry, School of Environment and Natural Resources, Ohio State University, Wooster, Canada \\ ${ }^{4}$ Department of Plant Science, College of Agriculture and Rural Transformation, University of Gondar, Gondar, Ethiopia
}

\section{Email address:}

hey.china@yahoo.com (H. B. Atinkut)

*Corresponding author

\section{To cite this article:}

Haimanot B. Atinkut, Abdulhamid K. Bedri, Assefa K. Sentayehu, Dick Warren. Farmers' Investment on Sustainable Agricultural Practices: Evidence from Amhara Region, Ethiopia. American Journal of Life Sciences. Vol. 5, No. 2, 2017, pp. 38-45. doi: 10.11648/j.ajls.20170502.11

Received: January 24, 2017; Accepted: February 14, 2017; Published: March 9, 2017

\begin{abstract}
Sustainable agricultural practices (SAPs) is a pooled of practices that increase productivity while conserving soil, which put on firm foundation of zero tillage, use of manure, legume intercropping and legume crop rotation. Despite use of SAPs is a panacea for aggravated soil erosion and nutrient depletion and maximizing crop produce, but it seems a plateau for farmers in Dangila district. This study, therefore, assessed factors that affecting of farmers decision behavior of implementing SAPs in Amhara region. The multistage sampling procedure was used to identify kebeles and sample respondents. Mixed nature of data were collected from sample respondents. Both descriptive statistics and Binary logit model was employed. The result of this study indicates that executing of SAPs is the aggregate of many factors, which should be given due attention in the transformation agriculture to environmentally friendly technologies and climate smart agricultural practice.
\end{abstract}

Keywords: Binary Logit, Degradation, Investment, Multistage Sampling, SAPs

\section{Introduction}

Ethiopian Economy is based on agriculture, which accounts 42 percent of GDP, 80 percent's of total employment, and 70 percent foreign currency [1]. Moreover, agriculture is the single most important source of food for the nation [2]. In countries where agriculture is the mainstay of the economy, soil fertility depletion in smallholder farming is one of the fundamental consequences of environmental problems causing low agricultural productivity. The dependency of livelihoods of majority of the people on agriculture results in fast and vast land degradation. Coupled with fast growing population, erratic rainfall and poverty; land degradation poses a serious threat for declining of agricultural productivity of the nation. The agriculture sector suffers from poor cultivation practices and frequent drought, but recent joint efforts by the government of Ethiopia and donors have strengthened with terrible starvation [3].

Land is the most important natural resource in this planet. It is a place from which humans beings are exploiting a number of resources [4]. Almost all necessary inputs and source of food found from land. However, land is losing its productivity due to a rising trend of land degradation $[5,6]$. The well-known proximate causes of land degradation are deforestation, overgrazing, limited soil and water conservation, burning of dung and crop residues, limited use of organic matter and declining use of fallow [7]. Land degradation is an old problem for Ethiopia but new in attracting attention of policy after 1973/74 the devastating famine in Wollo. Although following this worse effect of land degradation, to overcome the problem, Ethiopia has been launch afforestation and conservation programs since 1980s with the support of government and non-governmental organization; however, success of it is limited $[8,9]$. 
This study was undertaken in Dangila district, one of 167 districts' in Amhara region [10], which faces soil erosion; due to continuous cropping, overgrazing, over population, little or no fallowing, limited use of chemical fertilizers, little use of manure and crop varieties and resulted decline of productivity. Despite of natural resource conservation program held in 1980s throughout the country in particular in Dangila district, thus have made conservation structures were not maintained or sustainable. The household decision to invest on land conservation may be thus depend on perception on the erosion problem, knowledge of household, technology, market, land and farm attributes [11, 8, 12].

The new agricultural paradigm concerns on save and grow compatible with idea of sustainable agriculture system. The principles of sustainable agricultural practices (SAPs') are environmentally friendly, resource conserving, technically viable, economically and socially acceptable [12] Most empirical works done in Sub Saharan Africa indicate that most of adoption studies to date conducted in the country broadly focused on emphasized for green revolution technologies (adoption of improved crop varieties, chemical fertilizer, modern beehives, physical and biological soil and water conservation measures in both arid and watershed areas, and crop protection (e.g., [13, 14,15]. The attention given for adoption of SAPs practices up to now is very low.

The main aim of this study was to understand farmers' decision to invest on SAPs in the study area. Therefore, knowing the potential benefits that SAPs may preserves advocacy for stakeholders specially, the lion-share smallholder farming households involve in this sector. In the presence of the yield maximizing farm inputs and information constraints farmers faced low productivity in developing countries, sustainable agriculture [16] that relies on renewable local farm resources presents desirable options for enhancing agricultural productivity.

Cognizant of the determinants of household choices of SAPs can provide insights into identifying target variables and areas that enhance the use of these practices [17]. The overall goal of this study is to explore factors that facilitate or impede farmers' use of sustainable agriculture practices and its association in Dangila district. Specifically this study intended to address; assess factors influencing or facilitating for the use of selected SAPS in the study area and explore the association of between soil erosion and SAPs.

\section{Materials and Methods}

Study area: Amhara region is one the ninth regions and it has 11 administrative zone. Dangila district is one of the 8 district $\mathrm{s}$ in Awi zone ${ }^{1}$ and 167 districts in Amhara region, Ethiopia. Geographically, Dangila is found 36 and $11.3^{\circ}$ latitude and $36.8^{\circ}$ longitude with an elevation of 2137 meters above sea level. This district has been practicing mixed farming. The district has a potential for production of many

1 Zone is an administrative structure unit of the current Ethiopian Government found between district and region since 1991 onwards. crops and favorable for livestock husbandry. It has also a potential for ground and surface water, beautiful topography for tourism attraction, honey production and other agricultural produces are the topical features. The general climate is moist subtropical (woina Dega) importance worldwide and limited coverage of Dega (cold) and Kola (warm climate). Based on records at Dangla town, annual temperature is about $17^{\circ} \mathrm{C}$ and the annual rain fall is $1578 \mathrm{~mm}$. Based on the 2007 national census conducted by the Central Statistical Agency of Ethiopia (CSA) [10], this district has a total population of 158,688 , of whom 80,235 are men and 78,453 women; 27,001 or $17.02 \%$ are urban inhabitants. According to district report in 2013, it has also 27 rural kebele administratives and 6 town kebeles. In Dangila district, in most kebeles ${ }^{2}$; cereals (tef, maize, sorghum, finger millet, barely, white), grains (chick pea, bean, lentil, pea, etc), oil crops (Niger seed, rape seed, sesame, ground nut), vegetables, fruits, sugarcane, and the like dominantly produced. Livestock husbandry is also the other livelihood strategies of farmers in this district. It has a large potential of cattle production. According to the Dangila Woreda ${ }^{3}$ Rural Development and Agricultural Planning Office [18, 19], the district has a livestock populations of cattle, 152032(local) and 4017 (cross), sheep (58243), goats (19659), mules (423), horses (564), donkeys (1050), poultry (87946) and bee colonies are kept in three categories of bee hives: traditional (1050), transitional (135) and modern (868) bee hives. As highland part of Northwestern Ethiopia, land degradation is a problem. Both government and farmers engaged in soil and water conservation measures and technology adoption in addition to chemical fertilizer use as immediate solution.

Study Design and Data Collection: In this study, both qualitative and quantitative data were collected to hit the stated objectives from primary and secondary data sources. Rich primary data sets were collected by household survey, focus group discussion, key informant interview, and onsite observation. Secondary data was collected from pertinent documents, government report, line agricultural offices, internet, library and other sources.

Sample Size and Determination: For this study a multistage stratified sampling techniques was applied by a researcher. In the first stage, purposive sampling was utilized to select Dangila district because of the presence of the practice. In the Second stage, the total rural kebeles administrative (RKA) stratified based on agro ecology then two kebeles' namely, Wufta-Datie and Demisa were selected. Finally, 120 sample households were selected by use of random sampling technique; from the two RKAs according to proportion to size the sample was taken.

Data Analysis and Presentation: For this study both descriptive statistics such as, frequency, mean, standard deviation, t-test, Chi-square, and binary logistic model were

\footnotetext{
2 Kebele is the smallest administrative unit of the current Ethiopian Government larger than village and less from district since 1991

3 Woreda, is local language (Amharic) equivalent of district
} 
applied. A binary logit model was used to explain factors impede or facilitate farmers investment decision on SAPs and helps to identify key variables affecting farmers' decisions to invest in this practice with the support of Stata software version 11.0 was analyzed.

Econometric model Choice and Parameter Estimation:

There is no inherently ordering in the decision process of investing in SAPs'. Whether or not a farmer invests a new technology assumes a yes or no answer, a typical case of dichotomous variable. For such type of response, a discrete model is a popular tool of analysis. In this model, the dependent variable is a binary assuming two values, 0 and 1 . Hence, for a farmer who invests the SAPs', the value $(\mathrm{y}=1)$ and for a farmer who does not invests, a value $(\mathrm{y}=0)$ will be assigned. Several models such as simple correlation, linear probability function, etc, can be used to analyze adoption behavior of farmers. But these models have limitations in that the t-ratios are incorrect, exhibit hetroscedasticity, non-normality, their estimated probabilities $(\mathrm{Pi})$ may be greater than one or below zero, and assume Pi increases linearly with $\mathrm{X}[20,21]$. The logit and probit models overcome these problems since both are based on a cumulative distribution function.

For the present study, however, we selected the logit model for the following reasons: 1) Probit and logit models are non linear (in the parameters) statistical models that achieve the objective of relating the choice probability $\mathrm{Pi}$, to explanatory factors in such a way that the probability remains in the $(0,1)$ interval. The logistic function is used because it represents a close approximation to the cumulative normal and is simpler to work with. The close similarity between the logit and probit models is confined to dichotomous dependent variables and; 3) In many cases logistic regression is preferred to the probit due to its link to other models such as linear probability model, and its simpler interpretability as the logarithm of the odds ratio and its eminence effort to retrospectively collected data analysis.

Following [20, 22 ] the logistic distribution for the investment of SAPs can be specified as:

$$
\mathrm{Pi}=\frac{1}{1+e^{-2 i}}
$$

Where, Pi is the probability of farmers invest in SAPs' for the ith farmer, e represents the base of natural logarithms and $\mathrm{Zi}$ is the function of a vector of $\mathrm{n}$ explanatory variables (X's) which is an underlying and unobservable index for the ith farmer (when $\mathrm{Zi}$ exceeds some threshold level $\left(\mathrm{Z}^{*}\right)$, the farmer is observed to be an investor; otherwise he is a noninvestor when $\mathrm{Zi}$ falls below the threshold value), and expressed as:

$$
\mathrm{Zi}=\alpha+\sum \beta i X i
$$

Where $\alpha$ is the intercept, $\beta \mathrm{i}$ is a vector of unknown slope coefficients and $\mathrm{X} 1, \mathrm{X} 2 \ldots \mathrm{Xn}$ represent the $\mathrm{n}$ explanatory variables.

The logit model assumes that the underlying stimulus index $(\mathrm{Zi})$ is a random variable which predicts the probability of investment of SAPs'. The slope tells how the log-odds in favor of investment on SAPs change as independent variables change.

One way of approaching the $(0,1)$ constraint problem that is imposed on the probability is to transform $\mathrm{P}$ to eliminate one or both constraints [22] in a ratio form. If $p$ is the probability of investing on SAPs then 1- Pi represents the probability of not investing and can be written as:

$$
1-\mathrm{Pi}=1-\frac{1}{1+e^{-2 i}}=\frac{e^{-z i}}{1+e^{-z i}}=\left(\frac{1}{1+e^{z i}}\right)
$$

Dividing equation (1) by equation (4) and simplifying gives

$$
\frac{p i}{1-p t}=\left(\frac{1+e^{z i}}{1+e^{-z i}}\right)=e^{z i}
$$

Equation (4) shows the odds ratio, which defines the probability of investing relative to non- investing.

Finally, the logit model is obtained by taking the logarithm of equation (5) as follows:

$$
\mathrm{Li}=\ln \left\{\frac{p i}{1-p t}\right\}
$$

Where, $\mathrm{Li}$ is $\log$ of the odds ratio in favor of SAPs' adoption, which is not only linear in $\mathrm{Xj}$, but also linear in the parameters. Thus, if the stochastic disturbance term, (Ui), is introduced, the logit model becomes:

$$
\mathrm{Zi}=\beta^{\circ}+\beta 1 X i+\beta 2 X 2 i+\cdots+\beta n X n i+u i .
$$

The probability of multicollinarity occurrence with continuous explanatory variables and discrete explanatory variables was checked by Variance inflation factor (VIF) and contingency coefficient (CC), accordingly [21].

Dependent variable: It represents the observable decision of farmers investment on SAPs and otherwise, a dummy variable. This outcome variable will be analyzed by binary logit model that will take the value 1 invest, and 0 noninvestor. It is hypothesized as farmers use SAPs more than one year and had practice at least two components of SAPs considered as investor and take the value " 1 ", and a farmer not totally practiced or invest will considered as non-investor and take the value " 0 ". Independent variable: It was hypothesized as farmer's decision to invest or reject multiple components of SAPs to gain its profit will highly influenced by different factors.

Table 1. Definition and units of measurement of the explanatory variables.

\begin{tabular}{ll}
\hline Variables & Definition and units of measurement \\
\hline SEXHH & Sex of household head $(1=$ Female, $2=$ Male $)$ \\
AGEHH & Age of household head in years \\
EDUHH & Educational status of household head $(0=$ illiterate, $1=$ literate $)$ \\
PARTADMIN & Household head's participation in kebele $(0=$ no, $1=$ yes $)$ \\
\hline
\end{tabular}




\begin{tabular}{ll}
\hline Variables & Definition and units of measurement \\
\hline DISTPLOT & Distance from residence to the plot(in minute) \\
FARMSIZE & Farm size in hectare \\
LANDTENURE & Land tenure $(0=$ insecure, and $1=$ secure $)$ \\
SOILFERT & Soil fertility status $(0=$ non-fertile, $1=$ less fertile and $2=$ fertile $)$ \\
TLU & Respondent's owned livestock (in tropical livestock unit $)$ \\
SLOPEPLOT & Slop of the plot $(0=$ flat and $1=$ otherwise $)$ \\
PLOT & Number of plots (in number $)$ \\
EXTENSION & Extension agent visit $(0=$ not-visited and $1=$ visited $)$ \\
LANDUSE & Land use $(0=$ forest $/$ woodland, $1=$ cropland and $2=$ pasture \\
LABOR & Labor availability $(0=$ not-available and $1=$ available $)$ \\
\hline
\end{tabular}

Source: own extraction

\section{Results and Discussion}

\subsection{Households Descriptions}

Gender of household head can influence adoption of new technology either being female headed or male headed. Male headed households have better chance for investing on land conservation because of the position they have and access of information as compared to their counter parts in the study area. Out of total sample respondents, female- headed accounted for only $17.5 \%$, while the rest $82.5 \%$ were male headed, respectively. Among female-headed respondents $20.9 \%, 6.9 \%$ were non-investors, and investors of SAPs, respectively. Accordingly, from total sample respondents $75.8 \%$ were non-investors and $24.2 \%$ were investors of among multiple components of SAPs.

As education status of household head increases, it is considered to increase the transfer of relevant information, awareness and mutual understanding about new idea, technology and innovation and as a results increase farmers' knowledge about the benefits, constraints and opportunities gain from implementing sustainable agricultural practices. Education provides something for farmers to arrest loss of soil fertility using various ways of soil fertility improving practices, productivity maximizing at the same time keeping soil health, traditional and improved soil conserving technologies, compost and agronomic practices. Out of total respondents $48.3 \%$ were literate and 51.7 were illiterate.

In the study area, household head with family size of less than or equal to 2 members constitutes $2.50 \%$; 3 to 5 members constitute $35 \%$; 6 to 10 members constitute $60.8 \%$ and 11 and above members constitutes $1.67 \%$. To illustrate this the one household who has more economical inactive family members, the household head always enforced to cultivate the same crop from season to season and year to year in order to close family members mouth. In contrary, economically active family members are assumed as labour. Thus, family members have indeterminate influence an investment on SAPs in the study area.

\subsection{Land Characteristics}

The land size holding of the sample farmers ranges from 0 to 3 hectares. The average land holding is known to be 2.2 hectares with a standard deviation of 0.2 hectares. This is slight greater than national average 1.5 hectare of land. The survey result indicated that about half of the respondents had farm size of greater than 2 hectares of land. On the average investors hold more land 2.4 hectare, and non-investors 2.0 hectare of land, respectively. This illustrates as household own more unit of land, the household inspired to make decision to invest new agricultural technology alternative.

\subsection{Soil Fertility Status and Conservation Measures}

In this study, farmers' perception to new technology can be seen with knowledge and understanding of soil fertility status, especially they compare with crop produce either increases or decreases. Farmers perceive and rated soil fertility of their land as fertile, less fertile and not fertile in the study area. Moreover, these farmers reflected their position and knowledge of soil erosion and nutrient depletion by actions they will ready for adoption of any soil improving and maximizing crop produce if the soil is highly depleted and decrease crop yield. This indicates that farmers' perception to their surrounding is good to keep soil fertility as the reaction they took to keep the produce in a way they want to produce the amount and type of crop. In the study area, both traditional and improved soil management and soil conservation measures practiced, include trench, grass vegetation (water logging plot), soil bunds, check dams, compost making, manure use, mulching \& crop residues, traditional ditches, terracing, and soil bund, stone bund when excess stone exist at the plot and high runoff prone plot. Elephant grass and sasbanean are planted for multipurpose in water logging farm lands.

\subsection{Labour Availability}

Family labor force is one of the productive forces in addition to land and capitals in agricultural activities such as; land preparation, seeding, weeding, harvesting and cattle rearing and ranching. In addition to the household head, other members of a farm family also work on the farm and offfarm. Usually husband, wife, son and/or daughters share farm activities. Women are actively involved in cropping activities during peak seasons, particularly in time of planting / sowing weeding and harvesting. On the other hand, adult men are responsible for almost all farm operations although their participation in the household activity is limited. The peak months are June, July, August, November, December and January.

Out of total sample respondents 85.8 percent reported as 
they face labour shortage problems and the remaining 14.2 not encounter labour shortage problem. Based on the peak agricultural season sample respondents reported that labour shortage occurrence $46.7 \%$ during land preparation, 83.5 during seeding, $71.7 \%$ during weeding time and $80 \%$ were during collecting and harvesting of crop to granary. With regard to labour availability $65 \%$ of sample respondent were reported as difficult to get and $35 \%$ were reported as easily access at the time of labour requirement.

\subsection{Distance}

With reference to distance traditionally land users classified their plots into two. Plot near to homesteads called back yard, whereas the farmstead plots are referred as Ersha.
Plot distance from the residence of the farmer affects, management attention, of the farmer by affecting the average time need to travel for applying manure and cattle dung, tree planting, and for SWC construction and timely maintenance.

\subsection{Summary of Descriptive Statistics}

The mean values of the continuous variables in both investor and non-investor groups were compared using t-test. The test is used to indicate the mean differences between groups. That is why the test was used to identify the mean difference between investors and otherwise, respondents. The t-values of 7 continuous variables were computed and out of these variables the two groups were found to be different significantly in 4 of them (Table 2).

Table 2. Mean differences of continuous variables.

\begin{tabular}{|c|c|c|c|c|}
\hline \multirow{2}{*}{ Continuous variable } & Non-investors & Investors & Total & T-value \\
\hline & Mean & Mean & Mean SD & \\
\hline AGE(in years) & 47.7 & 44.7 & 43.710 .9 & $-1.408 * *$ \\
\hline FAMSIZE & 6.08 & 6.19 & 6.171 .99 & -0.282 \\
\hline FARMEXP & 21.1 & 21.8 & 21.79 .52 & -0.324 \\
\hline TOTALAND(ha) & 1.58 & 1.95 & 1.830 .93 & $-2.034 * *$ \\
\hline TLU & 7.39 & 8.90 & 8.434 .46 & $-1.727 * *$ \\
\hline MAINMARK & 149.2 & 151.3 & 150.727 .7 & -0.388 \\
\hline
\end{tabular}

*** Significant at $1 \%$ probability level; ** Significant at $5 \%$ probability level

Source: own survey, 2014

Accordingly, the mean differences of the variables of age of the household head (Age), household total land holding (TOTALAND) and total tropical livestock unit (TLU) were significant at $5 \%$ probability level where as the distance between farmers resident to the plot was significant at $1 \%$ probability level. In this respect, a chi-square test was used to examine the existence of statistically significant relationships between the three groups.

\subsection{Econometric Model Results}

Binary logit model was used to identify potential variables determine farmers investment decision on sustainable agricultural practices. Multicollinearity diagnostics test was done to check the presence of high collinearity among and between each independent variable. Different methods were employed to check the presence of multicollinearity for continuous and discrete explanatory variables. Variance inflating factor (VIF) was used to check for multicollinearity problem among and between continuous variables. For continuous variables coefficient of contingency (CC) was computed using Stata11 version. For this case, based on the results of the diagnostic tests for both discrete and continuous variables, no variable was found to be highly correlated or associated with one or more of other variables.

Fourteen variables were hypothesized to influence farmers' decision to invest on SAPs' and all variables were entered to the model. Out of the variables analyzed, the coefficients of 11 variables, namely sex, age, participation in kebele, soil fertility status, slope of the plot, number of plots, plot distant, land use, labor, TLU, and extension contact were significantly different from zero and found to be significant to affect the investment on SAPs' of the households in the study area. The maximum likelihood estimates of the binary logit model result shows that the household investment on SAPs' is determined by the interaction of several potential socio-economic factors. To check measure of goodness of fit in logistic regression analysis, the likelihood ratio test (LR) that follows chi-square distribution with degree of freedom (DF) equal to number of explanatory variables included in the model [23]. Accordingly, the chi-square computed shows that, the model was significant at $1 \%$ significance level. This indicates that the null hypothesis stating the coefficients of explanatory variables less the intercept are equal to zero was rejected and the alternative hypothesis of non- zero slope was accepted.

Another comparatively simple measure of goodness of fit was the count $\mathrm{R}^{2}$ obtained by dividing the number of prediction to the total number of sample. In this regard the count $\mathrm{R}^{2}$ was calculated to be 51.9 (78 out of 91 for nonconserving and 20 out of 29 for land conserving households) that indicate the model correctly predicts the observed values. The sensitivity, the number of investor households correctly predicted by the model was 84.0 percent and specifies, the number of non-investor households correctly predicted was 92.7 percent observation. Thus the model predicts both non-investor and investor household groups fairly and accurately (Table3). 
Table 3. Empirical result of binary logit model.

\begin{tabular}{lllll}
\hline Variable & Coeff & Odds ratio & S. E & Significance level \\
\hline CONS & -15.369 & & 3.965 & 0.000 \\
SEHH & 3.540 & 34.474 & 1.588 & 0.018 \\
AGEHH & 0.158 & 1.171 & 0.748 & 0.001 \\
EDUHH & 0.015 & 1.016 & 1.240 & 0.984 \\
PARTADMIN & 3.374 & 0.034 & 0.405 & 0.007 \\
FARMSIZE & 0.219 & 1.245 & 0.822 & 0.588 \\
LANDTENURE & -1.087 & 0.337 & 0.727 & 0.186 \\
SOILFERTLITY & 1.564 & 4.780 & 0.020 & 0.031 \\
SLOPEPLOT & -2.767 & 0.131 & 0.449 & 0.011 \\
PLOT & -2.445 & 5.087 & 0.671 & 0.000 \\
DISTPLOT & -0.021 & 0.980 & 0.090 & 0.100 \\
LANDUSE & -1.327 & 0.265 & 1.006 & 0.048 \\
LABOR & 1.570 & 25.406 & 1.519 & 0.045 \\
TLU & -0.161 & 0.851 & 0.134 & 0.073 \\
EXTENSION & 3.359 & 28.774 & 1.021 & 0.001 \\
\hline
\end{tabular}

Source: Own survey, 2014

Sex: Sex of household head was significant at $5 \%$ significance level and positively related with investment of SAPs' the households in the study area. This implies that, other things remaining constant, male-headed households are more likely to be investors on SAPs' than female headed households. The possible explanation for this would be male headed households have better access to farmland, labour, agricultural technologies and improved practices which all these increase crop yield and thus more investor on SAPs' than female headed households by a factor of 34.474 .

Age: This variable is significant at $1 \%$ and positively related to investors of SAPs' in the study area. This implies that, other things remaining the same, as age of house hold head increases by one year, the likely probability to become investor increases by a factor of 1.171. An increase in age of the household gives the chance to evaluate pros and cons of sustainable agricultural technologies. Thus, an increase in age is related negatively with non-investor on SAPs' of households. This finding was in agreement to some research evidences, that age has positive and significant impact on investment of land conservation technologies.

Participation in kebele administration: This variable was strongly significant at $1 \%$ significance level and positively related to investors in the study area. This implies that, other things remaining constant, as a farmer get position and participate in kebele administration, it gives the chance to familiar with new information and continuous to update as compared to non-participant being investor will be decrease 0.034 as not participate in kebele administration.

Soil fertility status: This variable was significant at $5 \%$ significant level and positively affects investor farmers in the study area. This implies that, assuming other things constant, as the soil fertility level decrease by one category from fertile to less fertile; the probability of the farmer's decision to invest SAPs to be increase by a factor of 4.780 and the reverse is true.

Slope of the plot: This variable was significant at $1 \%$ probability level and negatively affects investor farmers as the degree of slope increases. This implies that, the remaining things constant, as the slope of the plot increases by one degree the probability of the farmer become investing on among multiple components SAPs'. As slope of the plot increase by one degree the respondent farmer to be investor likely decrease by a factor of 0.131 as compared to noninvestors.

Number of plot: This variable was strongly significant at $1 \%$ significant level and negatively affects investor farmers when the number of plot increases. This implies that, assuming the remaining things constant, as the number of plot increases by one plot farmers exposed to transportation transaction cost on foot. As the number of the plot increase by a unit the household to be investor decease by a factor of 5.087as compared to non-investor farmers.

Distance to the plot: This variable was significant at $10 \%$ significant level and negatively affects investor farmers as the distance increases by a minute in the study area. This implies that, the remaining things the same, as the distance of the plot to the resident increases by one minute the probability of farmers investing SAPs' on his/her plot will likely decrease by 0.980 as compared to non- investor farmers.

Land use: This variable was significant at 5\% significant level and negatively influences farmer's decision to investment on sustainable land conservation strategies. This implies that, the remaining things constant, as the land use changes by season from crop land to wood or from crop land to grazing land the probability farmers investing on SAPs' will likely decrease by 0.265 as compared to non-investors and, otherwise.

Labor availability: This variable was significant at 5\% level of significance and positively influences decision of farmer's investing on SAPs' as they have one more labour unit. This implies that, assuming other things remaining the same, as labor availability increases by one unit the probability of farmers shift to investing on SAPs' will likely increase by 25.406 as compared to non-investors.

Total livestock owned: Livestock had a significant and negative impact on the household adoption of SAPs in the study area. The negative sign of slope coefficient indicates that when livestock owned increase by one TLU, the probability of a household to become investor of SAPs', decrease by a factor of 0.851 . The possible explanation for this result is that as farmers have large number of livestock (ox, cow, heifer, calf, donkey, goat, sheep and chicken) they become in low position to be investor than farmers who have few livestock.

Moreover, livestock (ox) serve as non-human labour, and source of dung i.e., draft power in land preparation that directly contributes to supply of labor and organic fertilizer.

Extension contact: This variable had significant and positive impact on farmers motivation to invest on SAPs' in the study area. This implies that, the remaining things constant, as the frequency of training and extension contact and /or visit of farmers by extension agents' and experts either from district or zonal level changes farmers mindset and increase knowledge of land conservation technologies. When extension contact and visit increases by frequency of contact or visit the household to be investor increase by a factor of 28.774 as compared to non- investor. 


\section{Conclusions and Other Implications}

Land degradation is an outdated and tied with bottlenecks, agricultural sector manifested by coupled with population growth at a faster rate, soil fertility depletion and decrease of crop yield, motivate to sustainable agricultural practices, which is agricultural-environmental management at short term or long term will be taken as a panacea.

For this study, data were collected from 120 farm households drawn randomly from Dangila district. The primary data were collected from semi-structured questionnaire and FGDs. Secondary data were collected from relevant GOs and NGOs and from pertinent documents to supplement the data obtained from survey. Results of this study indicated that sex of household head, age, participation in kebele administration, slope of the plot, distance to the plot, total livestock owned, land use, number of plot, labour availability and extension contact were significantly affects farmers decision to invest on SAPs'.

The paper suggests after careful examining adoption challenges in the face of soil nutrient loss. To alleviate problems of soil health problem and land degradation in the Study area, all concerned bodies including government, NGOs, academia, farmers, environmentalists and advocators should work together. The government can better reduce the problem by preparing different incentive packages for frontline farmers who are engaged in land conservation. Local NGOs which have a trust by local community can involve in awareness creation and empowerment on the land degradation consequences and adopting SAPs is the merely Option. NGOs might participate in provision of training for experts. The academia and other stakeholder might involve in incorporating sustainable land management on educational curriculum as a course, conducting research on better solutions of the gap between new technology adoption and farmers as well as pointing out other technology alternatives. Promotion organic agriculture, agronomic practices and expansion with market price adjustment on such produce will be the governments elephant-share job.

This is therefore, put the way forward based on the gabs o the extension system operating in the areas and elsewhere, need to be strengthened further to increase the flow of information for rural development. Participatory community based approaches involving the stakeholders in planning and implementation are necessary in order to create a higher ownership attitude. Clear messages on conservation agriculture practices should be included in the normal extension packages and training of both village extension workers and farmers should be emphasized so as to improve their understanding and skills.

\section{References}

[1] Central Statistical Agency (CSA). Agricultural Statistics Report Inter-sampling Census of Ethiopian population. Addis Ababa, Ethiopia. June, 2013.
[2] World Bank. Ethiopia: The World Fact book: http://www.cia.gov/library/publications/the-worldfactbook/fields/2116.html accessed.2013.

[3] Mesfin Dessalegn. Challenges and Prospects of Land Rehabilitation Practices: A case of Angacha Woreda. Kambata Tambaro Zone, SNNPR. MA Thesis submitted to School of Graduate Studies, College of Developmental Studies, Addis Ababa University, Addis Ababa, Ethiopia. 2010.

[4] Taffa Tulu. Soil and Water Conservation for Sustainable Agriculture. Mega Publishing Enterprise, Addis Ababa Ethiopia. 2002.

[5] Wagayehu Bekele. Economics of soil and water conservation: Theory and empirical application to subsistence farming in the Eastern Ethiopia highlands. $\mathrm{PhD}$ Dissertation, Swedish university of Agricultural Sciences, Uppsala, Sweden.2003.

[6] Woldeamlak Bewket and Sterk G. Dynamics in land cover and its effect on stream flow in the Chemoga watershed, Blue Nile basin, Ethiopia. Hydrological processes. 19, 445-458.2003 (2005). Published online 16 September 2004 in Wiley InterScience www.interscience.wiley.com). DOI: 10.1002/hyp. 5542.

[7] FAO (Food and Agricultural Organization).1995. Land and environmental degradation in Africa: Issues and options for sustainable economic development with transformation, Monograph, No.10: 1-66.

[8] Bekele Shiferaw. and S. Holden. Resource degradation and adoption of land conservation technologies in the Ethiopian Highlands: A case study in Andit Tid, North Shewa. The Journal of the International Association of Agricultural Economics, 18 (3): 233-247. 1998.

[9] Bishaw.2003. Deforestation and Land Degradation on Ethiopian Highlands: A strategy for Forest Recovery. Oregon University Press, USA.

[10] Central Statistical Agency (CSA). National Census of Ethiopian population. Addis Ababa, Ethiopia. May, 2009.

[11] Ervin C. A. and Ervin E. D. 1982. Factors Affecting the Use of Soil Conservation Practices: Hypothesis, Evidence and Policy Implications. Land Economics, 58 (3), 277-292.

[12] FAO (Food and Agricultural Organization). How do markets encourage the adoption of sustainable practices? The role of institutional innovations in developing countries, A. Loconto, A. S. Poisot and P. Santacoloma. Rome. (Forthcoming). 2016.

[13] Berhanu Gebremedhin and S. M. Swinton. Investment in Soil Conservation in Northern Ethiopia: The Role of Land Tenure Security and Public Programs. Journal of Agricultural Economics, 29: 69-84. 2003.

[14] Isham J. The Effect of Social Capital on Fertilizer Adoption: Evidence from Rural Tanzania. The Journal of African Economies. January 31, 2002.

[15] Kassie M., Zikhali P. Pender J. and Kohlin G. The economics of sustainable land management practices in the Ethiopian highlands. Journal of Agricultural Economics. 61: 605-627. 2011.

[16] Hailemariam Teklewold, Menale Kassie and Bekele Shiferaw. Adoption of Multiple Sustainable Agricultural Practices in Rural Ethiopia. Journal of Agricultural Economics, Vol. 64, No. 3, 2013, 597-623. doi: 10.1111/1477-9552.12011., 2012. 
[17] Dangila Woreda Rural Development and Agricultural planning office annual report. 2014.

[18] BOEFD. Annual report for Bureau of Finance and Economic Development. Amhara National Regional State, Ethiopia. (2): 15-23. 2009.

[19] Maddala G. S. Limited Dependent and Qualitative Variables in Econometrics. Cambridge University Press, New York. 19983.
[20] Gujarati D. Basic econometrics. 3rd (ed). Mc Graw-hill, Inc., New York.1995.

[21] Aldrich J. and Nelson F. Linear Probability, Logit and Probit Models: Quantitative applications in the Social Science: Sera Miller McCun Sage pub Inc., University of Minnesota \& Iowa. 1984

[22] Gujarati D. N. Basic Economics.4th(ed), McGraw Hill, Inc. New York. 2003. 